\title{
Educação física escolar sob o olhar dos alunos do ensino médio
}

\author{
Rennan Ripari \\ Centro Universitário Adventista de São Paulo, campus Hortolândia (UNASP-HT) \\ rennan.ripari01@gmail.com \\ Magda Jaciara Andrade de Barros \\ Centro Universitário Adventista de São Paulo, campus Hortolândia (UNASP-HT) e \\ Universidade Estadual de Campinas (UNICAMP) \\ magda.andrade3@ hotmail.com \\ Josiane Fujisawa Filus de Freitas \\ Universidade Federal da Grade Dourados (UFGD) \\ josianefffreitas@ufgd.edu.br \\ Thiago José Leonardi \\ Universidade Federal do Rio Grande do Sul \\ (UFRGS) thiago_leonardi@yahoo.com.
}

Cita sugerida: Ripari, R., Andrade de Barros, M. J., Fujisawa Filus de Freitas, J. y Leonardi, T. J. (2018). Educação física escolar sob o olhar dos alunos do ensino médio. Educación Física y Ciencia, 20 (2), e049. https://doi.org/10.24215/1514-0105e049

Recibido: 17 septiembre 2017 - Aceptado: 02 febrero 2018 - Publicado: 27 abril 2018

(c) (i) (2) Esta obra está bajo licencia Creative Commons Atribución-NoComercial-CompartirIgual 4.0 Internacional

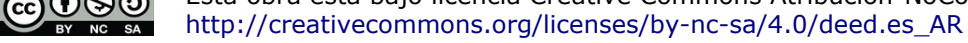




\title{
Educação física escolar sob o olhar dos alunos do ensino médio
}

Physical Education at school from the view of high school students

\author{
Rennan Ripari \\ Centro Universitário Adventista de São Paulo, campus \\ Hortolândia (UNASP-HT), Brasil \\ rennan.ripari01@gmail.com \\ Magda Jaciara Andrade de Barros \\ Centro Universitário Adventista de São Paulo, campus \\ Hortolândia (UNASP-HT) e Universidade Estadual de \\ Campinas (UNICAMP), Brasil \\ magda.andrade3@hotmail.com \\ Josiane Fujisawa Filus de Freitas \\ Universidade Federal da Grade Dourados (UFGD), Brasil \\ josianefffreitas@ufgd.edu.br \\ Thiago José Leonardi \\ Universidade Federal do Rio Grande do Sul (UFRGS), \\ Brasil \\ thiago_leonardi@yahoo.com.br
}

\section{Resumo:}

O objetivo do presente estudo foi verificar a opinião que o aluno tem sobre a Educação Física escolar. Especificamente procurouse investigar as opiniões dos alunos do Ensino Médio a respeito das aulas de Educação Física e qual a importância da disciplina. Os dados foram coletados a partir da aplicação de um questionário contendo 14 questões a 205 alunos divididos entre $1^{\circ} \mathrm{e} 3^{\circ}$ ano do Ensino Médio de escolas públicas e particulares da Região Metropolitana de Campinas, no Brasil. Com este estudo constatamos que na opinião dos alunos, a Educação Física é uma disciplina atrativa, porém não a consideram como uma das mais importantes.

PaLAVras-chaVe: Educação Física, Escola, Ensino Médio, Escolares.

\section{Abstract:}

The aim of this study was to see the opinion of students about Physical Education at school. Specifically, we studied the opinion of High School students about Physical Education classes and the importance of its content. We collected data applying a questionnaire with 14 questions in 205 students of first and third year of High School in public and private schools of Metropolitan Region of Campinas, at Brazil. We conclude that Physical Education is an attractive discipline though the students did not consider it the most important one.

KEYWORDS: Physical Education, school High School, Students. 


\section{INTRODUÇÃo:}

Quando a criança adentra ao mundo escolar, um novo ambiente repleto de possibilidades, vai aos poucos criando uma visão sobre o novo ambiente de aprendizagem, formando opiniões sobre professores, aulas, e colegas de turma(Freitas, da Silva, Lacerda, \& Leonardi, 2016).

Em relação à Educação Física Escolar, o aluno tem uma imagem fortemente valorizada da disciplina relacionando-a com liberdade, alegria, interesse, beleza e prazer, e ainda, com distração e não ao trabalho (Caviglioli, 1976). A opinião dos alunos se modifica ao longo das séries em função da faixa etária; dos 11 aos 13 anos os pré-adolescentes manifestam, em relação ao esporte, uma grande espontaneidade e entusiasmo; dos 14 aos 16 anos é um período em que há grandes variações individuais, os ritmos tornam-se mais variados, os alunos mais reservados e menos ativos; dos 11 aos 14 anos $90 \%$ dos alunos participam regularmente das atividades corporais na escola, dos 15 aos 16 anos este número chega a cair para 83\% (Caviglioli, 1976). Mesmo a Educação Física sendo um componente curricular obrigatório no Ensino Médio, somente 80\% afirmaram participar regularmente das aulas (Ferreira, Graebner, \& Matias, 2014). As participações dos alunos nas aulas também são influenciadas por sua personalidade, suas experiências individuais e o ambiente social da escola(Bidutte, 2001).

A disciplina de educação física como componente curricular obrigatório da Educação Básica assume importantes funções na sociedade contemporânea, entre elas: introduzir e integrar o aluno na cultura corporal de movimento (Darido, 2004). A Educação Física tem como pressuposto o desenvolvimento omnilateral do homem a partir das práticas corporais (de Oliveira, 2006) e deve proporcionar aos alunos vivências motoras que podem favorecer, ao longo do tempo, a adoção de um estilo de vida fisicamente ativo(Standage, Duda, \& Ntoumanis, 2003).

Escola não é clube. Escola não é academia de ginástica. Escola não é centro de treinamento esportivo. A escola não é a rua, ou a praça do bairro. Escola não é tempo nem "equipamento" de lazer. Embora possa estabelecer relações com todos esses lugares, a escola é um tempo e um lugar singular, que não pode ser nem confundido com (nem substituído por) nenhum desses (Vago, 2009, p. 26).

O Currículo do Estado de São Paulo entende que a Educação Física escolar deve tratar pedagogicamente de conteúdos culturais relacionados ao movimentar-se humano, visto que ao longo da evolução humana e social, construíram-se conhecimentos ligados ao uso do corpo e ao seu movimentar-se. A Educação Física trata da cultura relacionada aos aspectos corporais, que se expressam de várias formas, como os jogos, ginástica, danças e atividades rítmicas, lutas e esportes (São Paulo, 2011).

A referência para a configuração dos conhecimentos em Educação Física, na Base Nacional Comum Curricular (BNCC), são as práticas corporais. Elas estão organizadas, com base nas seguintes manifestações da cultura corporal de movimento: brincadeiras e jogos, danças, esportes, ginásticas, lutas e práticas corporais de aventura (Ministerio de Educación, 2016).

Mais recentemente, o ensino da Educação Física passou a tematizar as práticas corporais na escola, concebendo-as como um conjunto de práticas sociais centradas no movimento, realizadas fora das obrigações laborais, domésticas, higiênicas, religiosas, nas quais os sujeitos se envolvem, em função de propósitos específicos, sem caráter instrumental (Ministerio de Educación, 2016, p. 100).

Nesse sentido, o presente estudo buscou verificar a opinião dos alunos do $1^{\circ} \mathrm{e} 3^{\circ}$ anos do ensino médio, da região metropolitana de Campinas-SP, a respeito das aulas de Educação Física na escola identificando qual a opinião deles sobre a importância da disciplina, como eles se sentem nas aulas e quais os conteúdos aprendidos. 


\section{Metodologia:}

O presente estudo tem caráter descritivo e possui desenho transversal. Participaram desta pesquisa 205 alunos do $1^{\circ}(\mathrm{n}=177)$ e $3^{\circ}$ ano $(\mathrm{n}=88)$ do Ensino Médio, estudantes de escolas públicas e particulares da Região Metropolitana de Campinas.

Inicialmente, solicitou-se a autorização da direção das escolas para a realização do estudo. Na sequência, foram entregues aos alunos os Termos de Consentimento Livre Esclarecido (TCLE). Não participaram desta pesquisa, os alunos que não entregaram o TCLE com a assinatura de seu representante legal. O presente estudo teve aprovação no comitê de ética e pesquisa local sob o CAAE 44616815.7.0000.5622.

O instrumento utilizado para a coleta de dados foi o questionário proposto por Darido(2004), o qual continha 14 questões. Dele, utilizamos 7 questões para este estudo. Para responder às questões cujos resultados estão representados nos gráficos 5 e 6 os alunos poderiam marcar mais de uma alternativa. Os questionários foram aplicados durante as aulas de Educação Física, sem a presença do professor responsável pela disciplina. Os dados foram tabulados em planilha ad hoc do software Excel for Windows versão $2016 \mathrm{e}$ analisados por meio de estatística descritiva.

\section{Resultados e Discussão:}

Nos resultados que serão apresentados a seguir foram utilizadas questões que abordaram as disciplinas que os alunos consideram mais e menos importantes, a disciplina preferida pelos alunos, como eles se sentem durante a aula de Educação Física, o que é ensinado nas aulas, qual a visão dos alunos sobre a Educação Física e seu professor.

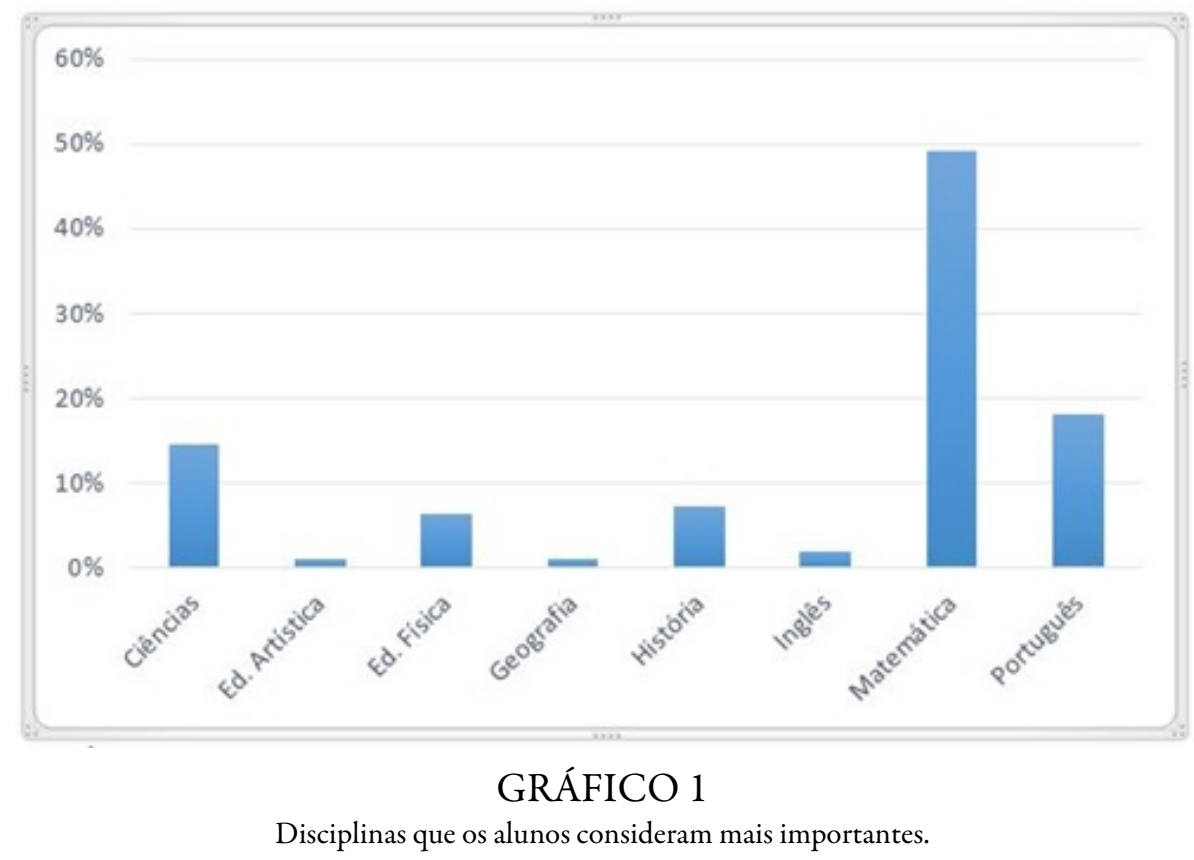

Podemos ver no gráfico 1, que na opinião dos alunos, a matéria mais importantes é Matemática com 49\%, Educação Física ficou um pouco distante com 6\%. Brandolin, Koslinski\& Soares (2015) também constataram que português $(50 \%)$ e matemática $(37,9 \%)$ são consideradas as disciplinas mais importantes pelos alunos.

Já no gráfico 2, quando perguntado das disciplinas menos importantes, Educação Artística aparece em primeiro com 63\%, e logo em seguida vem a Educação Física com 9\%. Um dos motivos que levam a 
desvalorização da disciplina de Educação Artística nas escolas é a falta de clareza sobre a função da Arte na educação (Franco, 1998). Teriam, então, os alunos clareza sobre a função da Educação Física na escola?

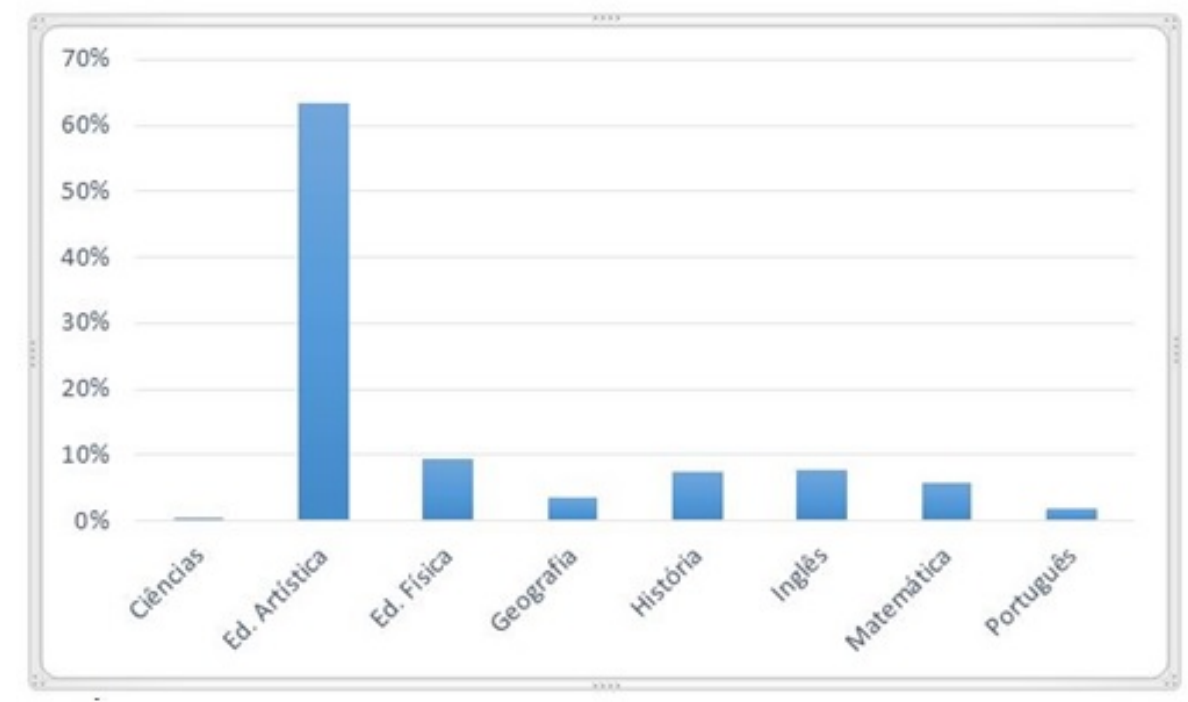

GRÁFICO 2

Disciplinas que os alunos consideram menos importantes.

As disciplinas mais valorizadas na opinião dos alunos são Português e Matemática, o que corrobora com a visão do senso comum uma concepção racionalista e funcionalista do ensino escolar (Lovisolo, 1995). Esses resultados ratificam o encontrado por Darido(2004), quando a autora afirma que "Estes resultados não chegam a surpreender já que a própria escola, na maioria dos casos, impõe um currículo com maior quantidade de aulas destas duas disciplinas, valorizando-as no interior da escola" (p. 69). Em outro estudo Ferreira, Graebner\& Matias (2014) afirmam que 40\% dos alunos dizem que a Educação Física não é tão importante quanto as demais disciplinas. Além disso, agrava-se o caso da Educação Física por não ser uma disciplina com conteúdos específicos no vestibular, visto esse ser um dos principais objetivos dos alunos do Ensino Médio (Darido, 2004).

Todavia, embora pouco valorizada no contexto escolar, a Educação Física é a disciplina preferida pelos alunos, conforme podemos observar no gráfico 3 . 


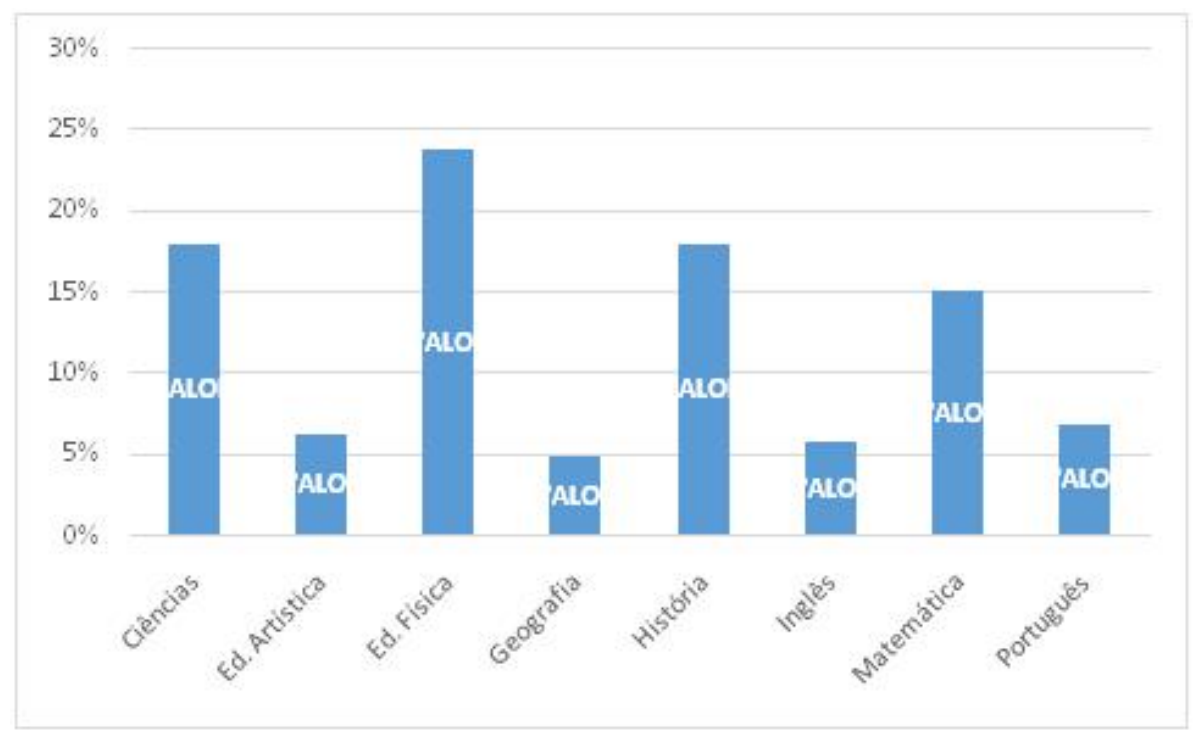

\section{GRÁFICO 3 \\ Disciplina preferida pelos alunos.}

Esses resultados mostram que a Educação Física está um pouco à frente das demais disciplinas, talvez seja pelo formato das aulas, longe de uma sala fechada com uma lousa e giz, onde os alunos copiam a matéria em suas cadeiras enfileiradas. Damasceno, de Freitas \& Leonardi (2017) constatam que as aulas de Educação Física chamam mais atenção dos alunos, por serem realizadas fora da sala, permitindo que ao aluno que se descontraia mais. Souza \&da Paixão (2015) diz que se compararmos a Educação Física aos demais componentes curriculares da educação básica, a Educação Física se configura na escola de uma maneira diferenciada das demais. No estudo realizado por Fonseca Filho, Marinho, Alves, Oliveira \& Fonseca (2011), dos 100 alunos que participaram da pesquisa, 43 deles também responderam que a disciplina de Educação Física é a que eles mais gostavam. Assim como, Betti e Liz (2003) obtiveram como resultado que a disciplina de Educação Física era a preferida, com $64,5 \%$ das indicações.

Freitas, Silva, Lacerda \& Leonardi (2016) comentam que esses resultados podem contribuir para uma elevada expectativa, proporcionando uma grande satisfação para o andamento da aula. Citam também que o professor deve ficar atento para que suas metas sejam traçadas e executadas atingindo os objetivos propostos e garantindo ao aluno não apenas o aprendizado, mas também alcançar suas expectativas.

Embora seja importante essa indicação de preferência da Educação Física frente às demais disciplinas, esse dado é inferior ao encontrado por Darido(2004), que indicava preferência da disciplina por $44 \%$ dos alunos do Ensino Médio pesquisados. Quando observamos alunos de séries anteriores, vemos uma preferência decrescente da disciplina com o passar dos anos, conforme mostra Darido(2004) e pesquisa recente realizada por Freitas, Silva, Lacerda \& Leonardi (2016) com alunos do $5^{\circ}$ ano do Ensino Fundamental, cuja preferência pela disciplina chega a 60\%. Quais motivos, então, levariam os alunos a gostar menos das aulas de educação física com o avanço da idade?

Buscamos compreender como os alunos se sentem quando estão nas aulas da disciplina (gráfico 4). 


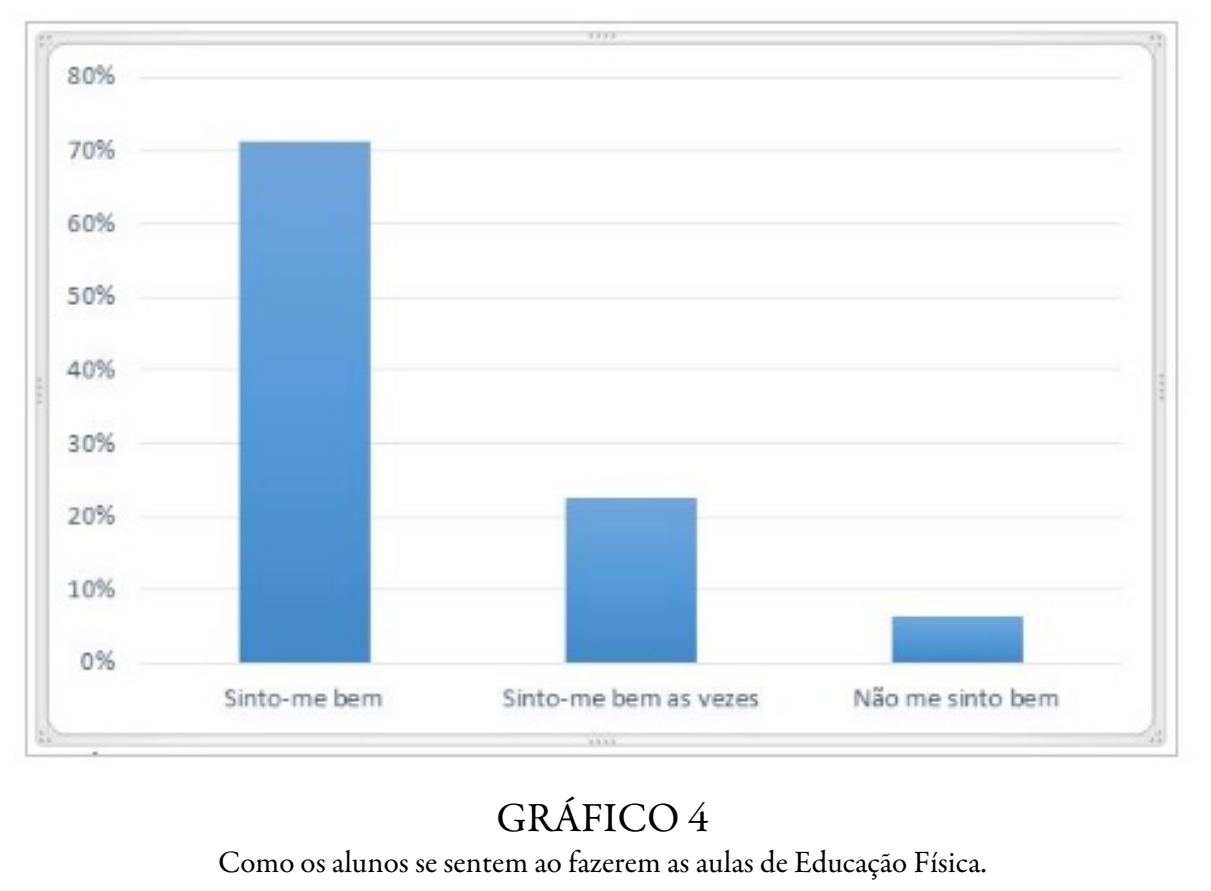

Embora $71 \%$ dos entrevistados dizem se sentir bem nas aulas, temos quase $30 \%$ dos alunos indicando sentir-se bem as vezes ou não se sentir bem. Uma limitação do questionário fechado é não dar voz às explicaçôes dos motivos que levam a essa resposta. No entanto, a literatura indica que dizer-se motivado para a aula pode ser uma evidência do estado de espírito com que se venha para a aula, ou com o conteúdo a ser desenvolvido (Schwartz, 1998). Betti (1995) afirma que o professor, o conteúdo e as condições de infraestrutura escolar são os principais fatores que contribuem para o prazer dos alunos nas aulas de Educação Física. Diante das questôes existentes no questionário proposto por Darido(2004), investigamos os conteúdos e a relação com o professor da disciplina. O gráfico 5 aponta os conteúdos mais abordados nas aulas de Educação Física.

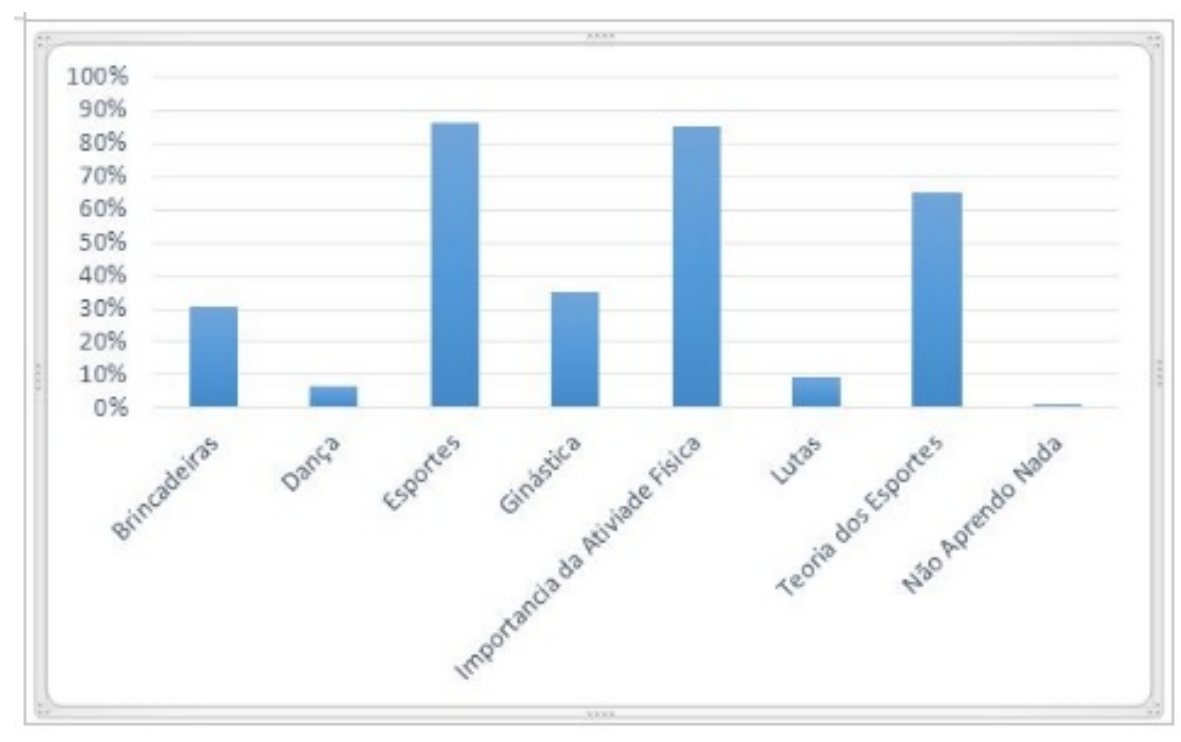

GRÁFICO 5

O que é ensinado nas aulas de Educação Física.

Evidencia-se nos resultados os esportes (enquanto prática e discussão teórica) junto à importância da atividade física como os principais conteúdos da aulas. Reflete-se aqui uma tendência apontada por 
Bracht(2010) da prática de esportes, segundo o autor sobretudo do quarteto fantástico (futsal, basquetebol, handebol e voleibol), nas aulas de Educação Física nas diferentes etapas do ensino básico. Vago (2009) diz que, a predominância e por muitas vezes quase que exclusiva presença de esportes nas aulas de Educação Física produz um efeito perverso na formação cultural dos alunos. Em seu estudo Darido(2004) diz, que à professores que afirmam que conteúdos como dança e lutas apresentam resistência por parte dos alunos, assim dificultando a inclusão destes conteúdos nas aulas. Kunz(2004) defende, ainda, em consonância com os dados aqui obtidos, que o conteúdo a ser ensinado na Educação Física Escolar não deve desenvolver somente as habilidades e técnicas, mas também incluir conteúdos de caráter teórico-prático. Daridoet al. (2001) afirmam que o aluno deve ter o conhecimento e o reconhecimento da importância da atividade física, o que ela significa; entender e compreender o porquê realizar atividade física, como realizá-la e quais os efeitos.

Defende-se na literatura que a Educação Física deve visar a formação do cidadão que possa usufruir compartilhar, produzir, reproduzir e transformar as formas culturais de jogos, esportes, ginásticas, lutas, atividades rítmicas e expressivas, exercícios físicos e as demais práticas que correspondem à cultura corporal de movimento de uma maneira geral (Darido, 2004). De acordo com a Secretaria de Educação do Estado de São Paulo o currículo apresenta uma perspectiva cultural e se ocupa em tratar da cultura de movimento, que são "os aspectos corporais, que se expressam de diversas formas, dentre as quais os jogos, as ginásticas, as danças, as lutas e os esportes” (São Paulo, 2013, p. 224). Salientam Milani \&Darido(2016, p. 456) que "Com a elaboração do currículo unificado no Estado de São Paulo, a sistematização dos conteúdos passou a ser uma realidade para a Educação Física escolar". Nesse contexto, a figura do professor é de extrema importância, uma vez que é ele geralmente responsável pela organização das aulas e escolha dos conteúdos (I. C. R. Betti, 1995). Alguns estudos analisaram que as expectativas dos alunos em relação à disciplina de Educação Física na escola, mostraram que os alunos questionam os conteúdos e as estratégias empregadas pelos seus professores (Betti, 1992). O professor tem a possibilidade de elaborar sua própria sistematização de conteúdos, adequando-se à realidade de sua região, com seus contextos culturais, considerando as demandas educacionais e as pessoas as quais os conteúdos serão ensinados(Palma, Oliveira, \& Palma, 2010). Antunes \& Dantas (2010) atribuem ao professor selecionar, "didatizar" e ensinar os conhecimentos ou conteúdos críticos formação do estudante.

A Educação Física como componente curricular da Educação básica deve assumir então uma outra tarefa, a de introduzir e integrar o aluno na cultura corporal de movimento, formando o cidadão que vai produzila, reproduzi-la e transformá-la, instrumentalizando-o para que o aluno possa usufruir do jogo, do esporte, das atividades rítmicas e dança, das ginásticas e práticas de aptidão física, tudo em benefício da qualidade da vida (Betti \& Zuliani, 2009).

Observando-se intrinsicamente a aula, foi solicitado aos alunos que classificassem suas aulas de Educação Física (gráfico 6). 


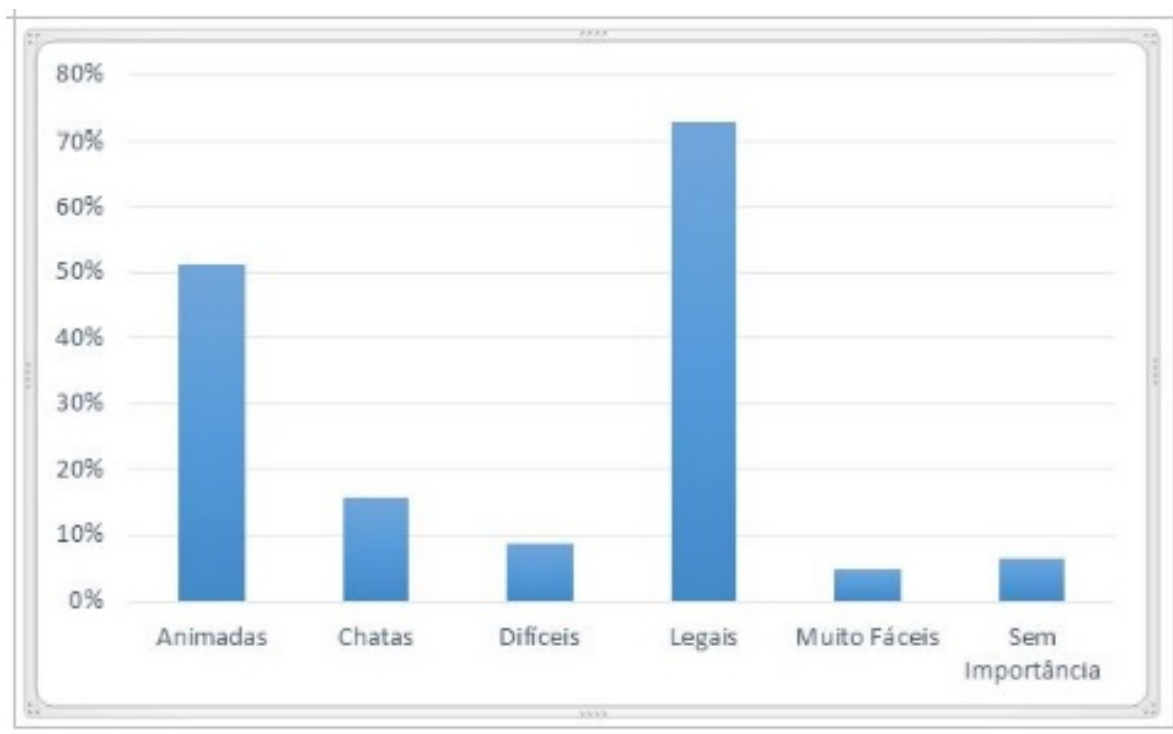

\section{GRÁFICO 6}

A opinião dos alunos sobre as aulas de Educação Física.

Chama-nos a atenção neste gráfico que $31 \%$ dos alunos classificam suas aulas como chatas, difíceis ou sem importância, corroborando com $29 \%$ que se sentem bem as vezes ou não se sentem bem nas aulas (gráfico 4). Outro dado coincidente são os $6 \%$ que dizem a aula não ter importância com os $9 \%$ que afirmam que a disciplina é a menos importante no contexto escolar (gráfico 2).

Em contrapartida, vimos no gráfico 5 à Educação Física, embora com maior ênfase na prática de esportes, tem um leque de conteúdos variados, podendo agradar a um maior número de alunos, colaborando para que a disciplina se torne mais interessante. Esse pode ser um dos motivos para a maior parte dos alunos acharem as aulas legais e/ou animadas.

Outro motivo para que os alunos gostem das aulas seria o próprio professor, a maneira que ele se comporta durante as aulas, suas atitudes e também se ele consegue motivar seus alunos. Freitas, Silva, Lacerda \& Leonardi (2016) apontam que alguns dos fatores que podem contribuir para os alunos terem essa opinião são as estratégias metodológicas usadas pelo professor, sua relação com os alunos, a maneira como ele fala e interage com a turma, bem como a estrutura da escola. Em seu estudo, Betti (1992) sinaliza que o professor é apontado pelos alunos como principal responsável por gostarem ou não da disciplina de Educação Física. "Todas as ações desenvolvidas pela escola devem integrar-se às necessidades de seus membros, buscando sempre uma construção coletiva e participativa” (Moreira, Pereira, \& Lopes, 2009, p. 138).

Vago (2009) afirma que a maneira como o professor compreende o corpo humano diz muito sobre seu projeto pedagógico, e que há impacto direto em seu modo de orientar e organizar o ensino que oferece a seus alunos. 


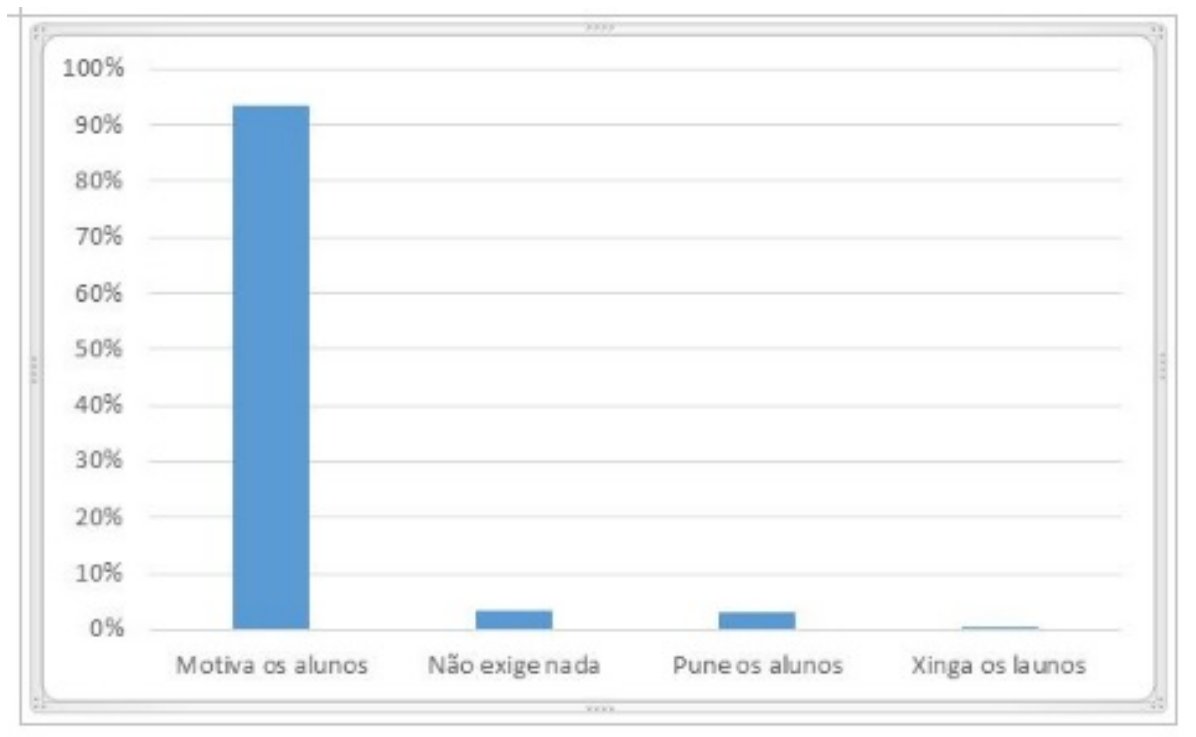

GRÁFICO 7

A opinião do aluno de seu professor atual de Educação Física.

Conforme gráfico 7 , vemos que $94 \%$ dos alunos dizem que o professor motiva seus alunos durante as aulas, o que reforça o dado anteriormente apresentado de que um dos conteúdos trabalhados é a importância da atividade física (gráfico 4). Mais uma vez a soma de $6 \%$ de alunos que dizem que o professor nada exige ou pune os alunos, reiterando valores de aspectos negativos apresentados nos gráficos 2,4 e 6 .

O professor é presença necessária e vital para os alunos, também recebeu muitas críticas, relacionadas a maneira de conversar com os alunos, à falta de paciência e diálogo; seu interesse e desinteresse não passam despercebidos pelos alunos (Betti, 1995). Betti \& $\operatorname{Liz}(2003$, p. 135)reiteram que “... o professor precisa gostar de seus alunos, respeita-los, ouvi-los, conhece-los”. A comunicação, a linguagem e o relacionamento interpessoal no ambiente escolar entre o professor e o aluno, são necessários para transformações sociais, afetivas e motoras(Baccarelli, Ruella, Galatti, \& Silvestre, 2010). Quando há uma relação de empatia, o professor motiva e reconhece o desempenho do aluno. O desempenho se torna uma motivação intrínseca, a qual pode ser acompanhada de uma motivação extrínseca, como os elogios e as recompensas (Lima, 2013). Freire \&Scaglia(2003) sugerem que o aprendizado oferecido pelos professores deve se dar de forma criativa e bem estruturada, proporcionando aos alunos prazer durante as aulas, pois, independente da atividade proposta pelo professor, a motivação deverá estar sempre presente para alcançar os objetivos da disciplina. Quando a motivação não é contemplada no planejamento da aula as experiências dos alunos no período escolar, principalmente no Ensino Médio, contribuem de forma negativa no interesse pela atividade física (Freire, 1991). Este fato, segundo (Daolio, 1996), desvaloriza as aulas de Educação Física e coloca em questão qual é a verdadeira colaboração desta disciplina para o desenvolvimento dos alunos.

\section{CONCLUSÃO:}

Apesar de ser a disciplina preferida pela maior parte dos alunos, a Educação Física não é considerada uma das matérias mais importantes no contexto escolar. No geral os alunos se sentem bem nas aulas de Educação Física, as quais são classificadas como legais e/ou divertidas pela maior parte dos entrevistados. Os alunos afirmam que os professores os motivam durante as aulas e citam diferentes tipos de conteúdos aprendidos em aula, sendo que o conteúdo mais frequente foi o relacionado aos esportes, em sua aplicação prática e conceituação teórica. 


\section{REFERÊNCIAS}

Antunes, F. H. C., \& Dantas, L. (2010). Sistematização do conhecimento declarativo em educação física escolar de $5^{a}$ à $8^{a}$ séries do ensino fundamental. Revista Brasileira de Educação Física e Esporte, 24(2), 205-221.

Baccarelli, M. R. T., Ruella, L. C., Galatti, L. R., \& Silvestre, C. H. (2010). Relacionamento interpessoal professoraluno na educação física. Conexões, 8(2), 19-32.

Betti, I. C. R. (1992). O prazer em aulas de educação física escolar: a perspectiva discente. Mestrado, Universidade Estadual de Campinas, Campinas.

Betti, I. C. R. (1995). Educação física escolar: a percepção discente. Revista Brasileira de Ciências do Esporte, 16(3), 158-167.

Betti, M., \& Liz, M. T. F. (2003). Educação física escolar: a perspectiva de alunas do ensino fundamental. Motriz, 9(3), 135-142.

Betti, M., \& Zuliani, L. R. (2009). Educação física escolar: uma proposta de diretrizes pedagógicas. Revista Mackenzie de Educação Física e Esporte, 1(1), 73-81.

Bidutte, L. d. C. (2001). Motivação nas aulas de educação física em uma escola particular. Psicologia Escolar e Educacional, 5(2), 49-58.

Bracht, V. (2010). Educação Física no Ensino Fundamental. Paper presented at the I seminário nacional: currículo em movimento, Belo Horizonte.

Brandolin, F., Koslinski, M., \& Soares, A. J. G. (2015). A percepção dos alunos sobre a educação física no ensino médio. Journal of Physical Education, 26(4), 601-610.

Caviglioli, B. (1976). Esporte e Adolescentes (1 ed.). Paris: J. VRIN.

Currículo do Estado de São Paulo: Linguagens, códigos e suas tecnologias (2011). Secretaria da Educação; coordenação geral, Maria Inês Fini; coordenação de área, Alice Vieira. - 2. ed. - São Paulo: SE,. 260 p. Recuperado de: http: //www.educacao.sp.gov.br/a2sitebox/arquivos/documentos/237.pdf

Damasceno, A. L., de Freitas, J. F. F., \& Leonardi, T. J. (2017). A motivação na participação dos alunos de $7^{\circ}$ e $9^{\circ}$ ano nas aulas de educação física. Horizontes, 4(8), 171-179.

Daolio, J. (1996). Educação Física Escolar: em busca da pluralidade. Revista Paulista de Educação Física(2), 40-42.

Darido, S. C. (2004). A educação física na escola e o processo de formação dos não praticantes de atividade física. Revista Brasileira de Educação Física e Esporte, 18(1), 61-80.

Darido, S. C., Rangel-Betti, I. C., Ramos, G. N. S., Galvão, Z., Ferreira, L. A., Mota e Silva, E. V.,Rodrigues, L.H., Sanches Neto, L., Pontes,G., Cunha, F. (2001). A educação física, a formação do cidadão e os parâmetros curriculares nacionais. Revista Paulista de Educação Física, São Paulo, 15(1), 17-32.

de Oliveira, M. A. T. (2006). Existe espaço para o ensino de Educação Física na escola básica? Pensar a Prática, 2, 119-135.

Ferreira, M. L. d. S., Graebner, L., \& Matias, T. S. (2014). Percepção de alunos sobre as aulas de educação física no ensino médio. Pensar prát.(Impr.), 17(3), 734-750.

Fonseca Filho, G. S., Marinho, G. M., Alves, J. M., Oliveira, D. A. S., \& Fagundes, J. L. C. (2011). Percepção dos alunos de uma escola pública em relação às aulas de educação física. Encontro Estadual de Didática e Prática de Ensino, 4, 57-70.

Franco, F. C. (1998). O professor de Arte: perfil do profissional que atua no ensino fundamental de escolas públicas paulistas, com alunos de 5a a 8a séries: São Paulo: PUC. Dissertação de mestrado.

Freire, J. B. (1991). Educação de corpo inteiro: teoria e prática da educação física (2 ed.). São Paulo: Scipione.

Freire, J. B., \& Scaglia, A. J. (2003). Educação como prática corporal (1 ed.). São Paulo: Scipione.

Freitas, J. F., da Silva, J. E. B., Lacerda, M. R. A., \& Leonardi, T. J. (2016). A identidade da educaçãofísica escolar sob o olhar dos alunos do $5^{\circ}$ ano do ensino fundamental I. Pensar a Prática, 19(2),396-409.

Kunz, E. (2004). Transformação didática-pedagógica do esporte (6 ed.). Ijuí: Unijuí. 
Lima, A. C. M. (2013). Motivação nas aulas de educação física.

Lovisolo, H. (1995). Educação física: a arte da mediação (1 ed.). Rio de Janeiro: Sprint.

Milani, A. G., \& Darido, S. C. (2016). Os conteúdos atitudinais no currículo de educação física do estado de São Paulo. Pensar a Prática, 19(2), 448-461.

Ministério da Educação (2016) Base Nacional Comum Curricular: Proposta Preliminar. Recuperado de:http://histor iadabncc.mec.gov.br/documentos/bncc-2versao.revista.pdf

Moreira, E. C., Pereira, R. S., \& Lopes, T. C. (2009). Indicativos que justificam uma Educação Física participada e planejada: uma investigação no Ensino Médio. Coleção Pesquisa em Educação Física, 8(2), 137-144.

Palma, A. P. T. V., Oliveira, A. A. B., \& Palma, J. A. V. (2010). Educação Física e a organização curricular: educação infantil, ensino fundamental, ensino médio. Londrina: Eduel.

Proposta curricular do Estado de São Paulo: Educação Física (2013). Secretaría de Educación. São Paulo.

Schwartz, G. M. (1998). As atividades expressivas no contexto da educação física: Parâmetros motivacionais e de aderência. Revista Mineira de Educação Física. Retrieved from <http://www.revistamineiradeefi.ufv.br/artigos/ arquivos/e855f3b de72b4f5a95f02420ffdaf746.pdf>

Souza, J. A., \& Paixão, J. A. (2015). A prática do bom professor de Educação Física na perspectiva dos alunos do ensino médio. Revista Brasileira de Estudos Pedagógicos, 96(243), 399-415.

Standage, M., Duda, J. L., \& Ntoumanis, N. (2003). A model of contextual motivation in physical education: Using constructs from self-determination and achievement goal theories to predict physical activity intentions. Journal of educational psychology, 95(1), 97.

Vago, T. M. (2009). Pensar a educação física na escola: para uma formação cultural da infância e da juventude. Cadernos de formação RBCE, $1(1), 25-42$. 